Special issue of the 3rd International Conference on Computational and Experimental Science and Engineering (ICCESEN 2016)

\title{
Investigation of Wear Strength of Blast Furnace Slag Blended Polymer Materials
}

\author{
I. Gunes ${ }^{a, *}$, T. UygunoĞLU ${ }^{b}$, A. EvCin ${ }^{c}$ And B. Ersoy ${ }^{d}$ \\ ${ }^{a}$ Afyon Kocatepe University, Metallurgy and Materials Engineering Department, Afyonkarahisar, Turkey \\ ${ }^{b}$ Afyon Kocatepe University, Civil Engineering Department, Afyonkarahisar, Turkey \\ ${ }^{c}$ Afyon Kocatepe University, Materials Science and Engineering Department, Afyonkarahisar, Turkey \\ ${ }^{d}$ Afyon Kocatepe University, Mining Engineering Department, Afyonkarahisar, Turkey
}

\begin{abstract}
Having symmetrical and balanced material properties, polymer matrix composites are increasingly becoming popular due to easiness of construction and are use in the production of aerospace and automotive structures. In the study, we developed polymer composites based on epoxy resins, containing up to 40 wt.\% of blast furnace slag and determined their pin-on-disc dynamic friction, wear, Shore hardness and surface roughness values. Wear tests were performed using a pin-on-disc under dry friction conditions, at the loads of $5,10,15$ and $30 \mathrm{~N}$, using slip velocity of $0.3 \mathrm{~m} / \mathrm{s}$ and along distance of $500 \mathrm{~m}$. The hardness and wear resistance values increased with the increase in the content of blast furnace slag. Showing the relationship between wear rate and hardness, an equation with parameters dependent on load was provided. There was an increase in the dynamic friction with an increase in the surface roughness. In addition, dynamic friction was an increasing function of the wear rate. The wear surfaces of the polymer composites were analyzed using scanning electron microscopy. It was observed that the wear rate of the epoxy composites and pure epoxy samples ranged from 19.85 to $171.42 \mathrm{~mm}^{3} / \mathrm{N} \mathrm{m}$.
\end{abstract}

DOI: 10.12693/APhysPolA.132.599

PACS/topics: Blast furnace slag containing, Epoxy composites, Hardness, Abrasive wear, Dynamic friction, Surface roughness

\section{Introduction}

To extract iron from ore, it is necessary to purify the ore from foreign substances it holds and remove the oxygen inside the iron oxide by resolving it. In order to carry out these processes, iron ore is heated and melted at high temperatures in blast furnaces. With high temperature in the furnace, residual molten iron, molten lime, silica, alumina, a slag composed of coking coal ash, and other foreign matters are generated while the carbon in the coking coal combines with the oxygen in the iron oxide and leaves the furnace as $\mathrm{CO}$ and $\mathrm{CO}_{2}$ gases.

Molten slag, which is cooled down and granulated, is referred to as "ground granulated blast furnace slag". Consuming a great amount of energy and emitting destructive greenhouse gases to the atmosphere during the production process, most of the binder materials have a significant role in environmental pollution. Therefore, binder users utilize various mineral additives to reduce the $\mathrm{CO}_{2}$ emission and to increase the production rate, by reducing the energy consumption. Granulated blast slag, which is one of those mineral additives, is formed during the production of pig iron in iron and steel factories and major part of it is ready to be used as an alternative binding material.

The use of industrial by-products, containing high percentage of silica and alumina as additives in cement or

*corresponding author; e-mail: igunes@aku.edu.tr concrete production, is a convenient area for the utilization of large volumes of waste materials, which will scale down environmental problems, to some extent. By preventing the rapid consumption of limited natural resources, these by-products will also provide the production of more inexpensive materials of higher quality than the traditional ones [1-5].

A polymer composite material is generally composed of two components; a matrix, also referred to as a continuous phase, and a filler, also referred to as reinforcement or, more broadly, dispersed phase. Additional compounds, mostly compatibilizers, are also used occasionally. The matrix integrates filler particles and allows the shaping of products appropriately and determines most of the physical and chemical properties of the material. The dispersed phase is responsible for the additional enhancement of the selected material properties. Compatibilizers are added in order to increase the interaction between the matrix and filler, and have a significant effect not only on the cohesion and homogeneity but also on processing properties and strength of the material [6-8].

Epoxy resins (EP) are thermoset resins with good thermal and environmental stability, and high strength and wear resistance. The combination of these properties enables the application of EP in polymer-based heavy duty sliding bearings. To this end, EP is usually compounded with such reinforcements as glass or carbon fibers, ceramic, mineral oxides and inorganic fillers. The use of fillers in polymeric composites helps to improve tensile and compressive strengths, tribological characteristics, toughness (including abrasion), dimensional stability, thermal stability, and other properties. 
Not only does the addition of fillers in polymeric composites yield higher mechanical strength, but also ensures cost reduction in terms of consumption of resin material [9-11].

The wear behavior of polymeric materials has drawn a considerable attention in recent years. Polymers and their composites are widely used in various applications, in which resistance to abrasive wear is of importance [12]. The areas of use of these composites range from machinery parts and biomedical joint replacements, to glazing materials, in which damage results in loss of optical properties. Due to their general resistance to corrosion, galling and seizure, tolerance to small misalignments and shock loading, and low coefficients of friction, polymers are ideal materials for bearing applications, such as those using glazing materials. They are also materials of choice due to their low density and high toughness along with high transparency.

The suitability of polymeric materials for abrasive wear conditions largely depends upon their mechanical loadcarrying capacities and wear rates. Factors, other than mechanical and tribological properties, which determine the suitability of polymeric materials, are low cost, simplicity of production, processing and practical limitations in application. The transfer capacity and buildup of a polymer film are also important aspects which have a role in the performance of polymers sliding against hard and smooth counter face. Efficiency of materials in reducing friction and wear depends on the structure of the molecular polymer and type of the counter face. However, the number of studies on the comparison of the tribological properties of composites under dry sliding and abrasive wear conditions is very small [13-17].

In general, these studies deal with the enhancement of the wear resistance of polymer materials [11-18]. Not releasing reaction products when cured and, therefore, having low cure shrinkage, epoxy resins are the most commonly used thermoset plastic materials in polymer matrix composites. They also have good adhesion to other materials, good chemical and environmental resistance and good chemical and insulating properties. This study, particularly, investigated the effect of blast furnace slag addition as filler on wear and friction characteristics of epoxy composites.

\section{Experimental studies}

The blast furnace slag (BFS) used in the study was supplied by Bolu Cement Factory in Bolu, Turkey. Its maximum particle size was $113.78 \mu \mathrm{m}$. The chemical components of the blast furnace slag are presented in Table I.

Commercially available Teknobond 300 epoxy resin, along with a hardener, was used as matrix material in the fabrication of different samples. Epoxy resin has a modulus of $3.42 \mathrm{GPa}$, and a density of $1100 \mathrm{~kg} / \mathrm{m}^{3}$. A mix ratio (by weight) of epoxy resin (2 parts) and hardener (1 part) was used for processing, as specified. The resin and hardener (Table II) were mixed in a beaker, using a rod, and
Chemical content of BFS.

\begin{tabular}{c|c|c|c|c|c|c|c|c}
\hline \hline Oxide & $\mathrm{SiO}_{2}$ & $\mathrm{CaO}$ & $\mathrm{Al}_{2} \mathrm{O}_{3}$ & $\mathrm{Fe}_{2} \mathrm{O}_{3}$ & $\mathrm{MgO}$ & $\mathrm{Na}_{2} \mathrm{O}$ & $\mathrm{K}_{2} \mathrm{O}$ & $\mathrm{LOI}$ \\
\hline $\begin{array}{c}\text { Content } \\
{[\%]}\end{array}$ & 32.8 & 39.8 & 11.8 & 4.15 & 1.45 & 0.51 & 0.91 & 8.58
\end{tabular}

it was made sure that no air was entrapped inside the solution. The production of the polymer matrix composite was carried out at room temperature. The resin, hardener and blast furnace slag were thoroughly mixed and then the mixture was placed in a mold which was coated with a separator. Silicon molds $(\varnothing 50 \mathrm{~mm})$ were used to cast the polymer matrix composite samples. Curing was performed at room temperature, approximately for $24 \mathrm{~h}$. After curing, the samples were de-molded.

TABLE II

Composition of epoxy based polymer composites.

\begin{tabular}{c|c|c|c}
\hline \hline Mixture code & $\begin{array}{c}\text { Epoxy resin* } \\
{\left[\mathrm{kg} / \mathrm{m}^{3}\right]}\end{array}$ & $\begin{array}{c}\text { Blast furnace } \\
\text { slag }\left[\mathrm{kg} / \mathrm{m}^{3}\right]\end{array}$ & $\begin{array}{c}\text { Hardness } \\
\left(H_{D}\right)\end{array}$ \\
\hline 0 BFS & 100 & - & 84 \\
$10 \mathrm{BFS}$ & 90 & 10 & 85.3 \\
$20 \mathrm{BFS}$ & 80 & 20 & 86.8 \\
$30 \mathrm{BFS}$ & 70 & 30 & 88.5 \\
$40 \mathrm{BFS}$ & 60 & 40 & 90.1
\end{tabular}

${ }^{*}$ Epoxy resin was used with hardener $(2: 1)$.

Wear tests were performed by using a ball-on-disc test device to obtain friction and wear values of the epoxybased samples. In the wear tests, WC-Co balls $(6 \mathrm{~mm}$ in diameter), supplied by H.C. Starck Ceramics GmbH, were used. Errors caused by the distortion of the surface were eliminated by using a separate abrasion element (WC-Co ball) for each test. The wear experiments were carried out in a ball-disc arrangement under dry friction conditions at room temperature, at the applied loads of $5,10,15$ and $30 \mathrm{~N}$, a slip velocity of $0.3 \mathrm{~m} / \mathrm{s}$ and a sliding distance of $500 \mathrm{~m}$. Before and after each wear test, each sample and abrasion element were cleaned with alcohol. After the test, the wear volumes of the samples were quantified by multiplying cross-sectional areas of wear by the width of the wear track, obtained using a Tribotechnic Rugosimeter. The wear rate was calculated using the following formula

$$
\text { Wear rate }=\frac{\text { Worn volume }}{(\text { Applied load } \times \text { Sliding distance })} \text {. }
$$

Sliding distance-dependent friction coefficients were obtained using a friction coefficient program. Surface profiles of the wear tracks on the samples and surface roughness values of the samples were measured using the Tribotechnic Rugosimeter.

\section{Results and discussion 3.1. Surface roughness}

Figure 1 shows the surface roughness values of the polymer composites with and without BFS. The surface 
roughness values of all series increased with the increase in BFS content.

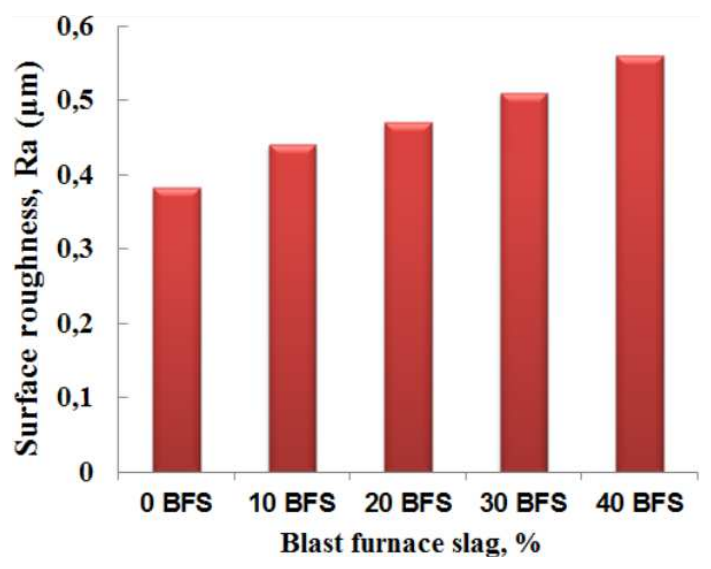

Fig. 1. Surface roughness values of epoxy composites with and without BFS.

\subsection{Friction coefficient and wear rate}

Friction coefficients at different loads, for pure epoxy and samples containing BFS are presented in Fig. 2. While the lowest friction coefficient of 0.015 was obtained from the pure epoxy samples, it has increased up to 0.062 in the series containing $40 \%$ of BFS material. The use of BFS in polymer composites yielded a higher friction coefficient, when compared to pure epoxy. The friction coefficient values of all series increased with the increase in the load. Figure 2 shows the load-dependent variation in friction values for BFS blends and pure epoxy based polymer composites. It is noteworthy that the friction, as a function of composition, was at the lowest level at loading force of $5 \mathrm{~N}$, for all series.

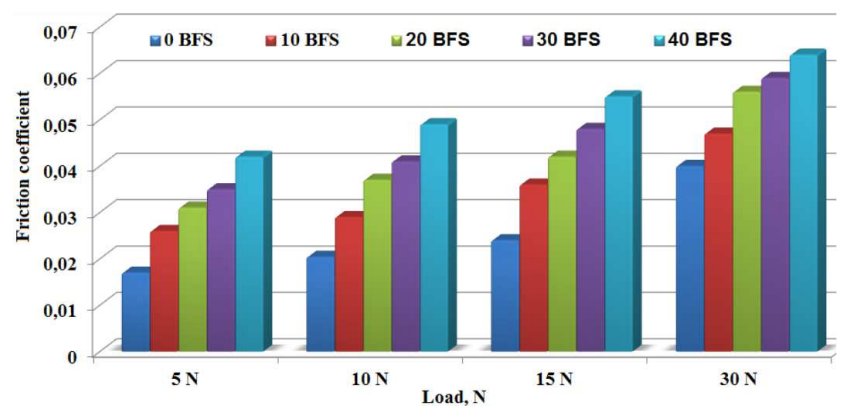

Fig. 2. Friction coefficient values of epoxy composites with blast furnace slag.

This situation can be accounted for by the "bumps" on the predominantly polymer composite surface. Bumps reduce friction as long as they are small. However, when the concentration of BFS material exceeded $10 \mathrm{wt} . \%$, surface areas of the the bumps have apparently increased, which resulted in an increase in the friction. On the other hand, when the amount of the load exceeded $5 \mathrm{~N}$, it led to an increase in the surface areas of the bumps and resulted in an increase of the friction. Figure 3 demonstrates the wear rate of the polymer composites for 5,10 , 15 and $30 \mathrm{~N}$, for varied blast furnace slag content.

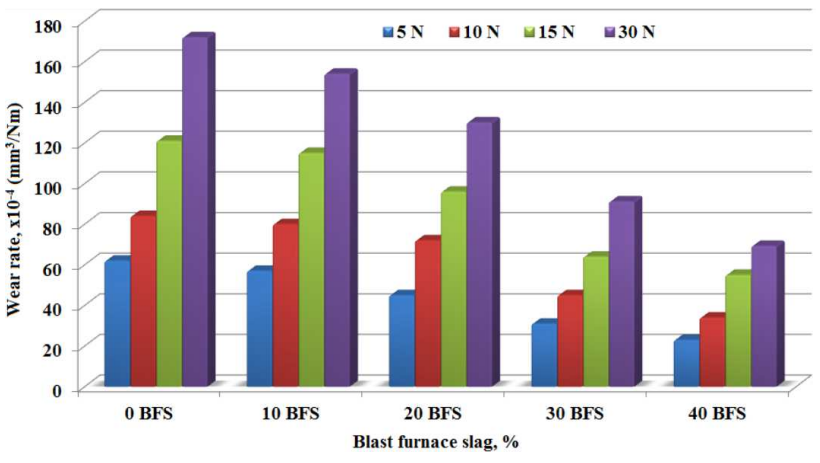

Fig. 3. Wear rates of epoxies for various BFS concentrations.

Figure 3 indicates that the wear rates of the composites decreased with the increase in the content of BFS material. The pure epoxy series yielded the highest wear rates at each loading condition. The wear rates ranged from $59.8 \times 10^{-4}$ to $19 \times 10^{-4} \mathrm{~mm}^{3} / \mathrm{Nm}$ at $5 \mathrm{~N}$, from $82 \times 10^{-4}$ to $36 \times 10^{-4} \mathrm{~mm}^{3} / \mathrm{N} \mathrm{m}$ at $10 \mathrm{~N}$, from $118 \times 10^{-4}$ to $47 \times 10^{-4} \mathrm{~mm}^{3} / \mathrm{Nm}$ at $15 \mathrm{~N}$ and from $170 \times 10^{-4}$ to $64 \times 10^{-4} \mathrm{~mm}^{3} / \mathrm{N} \mathrm{m}$ at $30 \mathrm{~N}$, depending on BFS content.

In other words, the enhancement in the wear resistance of the polymer composites at $30 \mathrm{~N}$ was about 2.84 times greater with the increase in BFS content. An increase in the ratio of the blast furnace slag additive resulted in a decrease in the wear rate. This means that adding BFS material makes the polymer material harder and also changes the characteristics of the surface. The wear strength was higher at high BFS ratio due to more homogenous distribution of particles with high resistance to abrasion.

Given the wear loading value, the wear rate values for all samples increased with load regardless of the ratio of BFS material. Due to the increase in abrasion and friction on surface of polymer composite, the wear rate increased with the increase in the load from 5 to $30 \mathrm{~N}$.

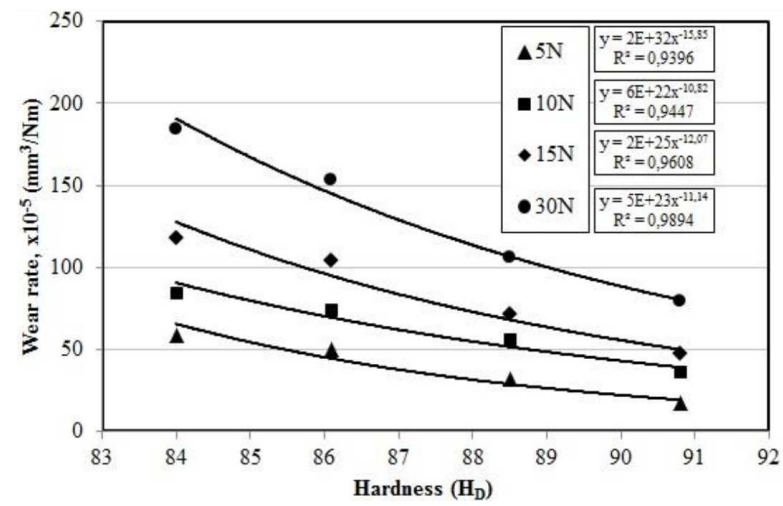

Fig. 4. Relationship between wear rate and hardness of the composites. Fitted mathematical expressions are shown in the insets. 
The relationship between the wear rate and hardness was investigated and is presented in Fig. 4. For each load, the wear resistance increased with the increase in the hardness. Respective equations were provided in insets of Fig. 4. The coefficient of determination $R^{2}$ was very close to 1.0 for each loading condition and the highest one was obtained for $30.0 \mathrm{~N}\left(R^{2}\right.$ corresponds to the perfect fit).

One of the important findings of this study was the relationship between hardness and wear rate for epoxybased and blast furnace slag containing polymer composites. The hardness values of the samples increased with an increase in BFS content. Therefore, the wear resistance of BFS-containing samples increased compared to pure epoxy (0 BFS), due to high hardness value of BFS blended polymer composites.

In order to carry out the analysis on the effect of surface quality on the tribological properties of the epoxybased polymer composites more easily, the calculated regression functions are provided in Fig. 5, which shows the dependence of the friction coefficient on the surface roughness. The relationship between the surface roughness and friction coefficient was lower at loading condition of $5 \mathrm{~N}(R=0.936)$, than at loading condition of $30 \mathrm{~N}(R=0.979)$. These results indicate that the relationship between the friction and surface roughness is better at high loading than at low loading.

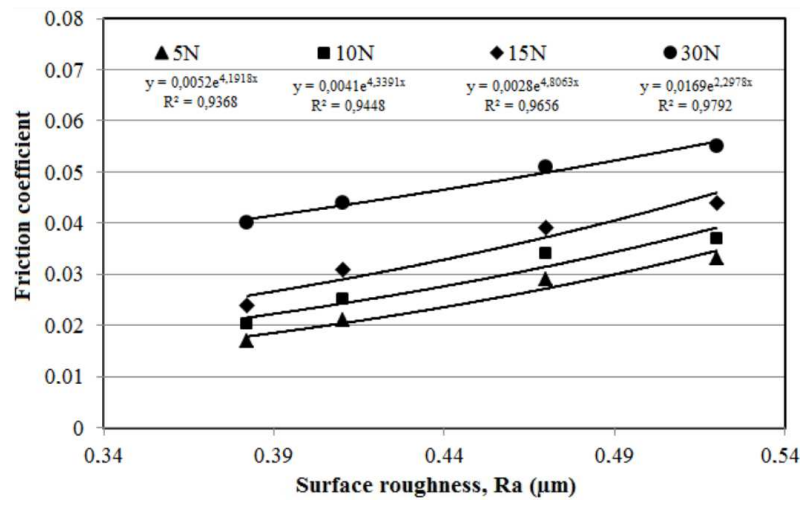

Fig. 5. Relationship between dynamic friction and surface roughness.

Figure 6 presents the wear SEM micrographs of the epoxy composites for various BFS concentrations, after tribometry. An increase in the load has enabled the pin to move over a wear border. The wear border made the movement of the ball more difficult at high loading condition (see Fig. 6) and in this situation the indenter had moved across the entire surface of each region [19]. The indenter is not just jumping from bump to bump, as it was doing with little contact with the surface between the bumps. This results in high friction values, in fact even higher for pure components [20,21].

The hardness values of the samples increased with the increase in BFS content. Therefore, the wear resistance increased, compared to the control samples, due to high

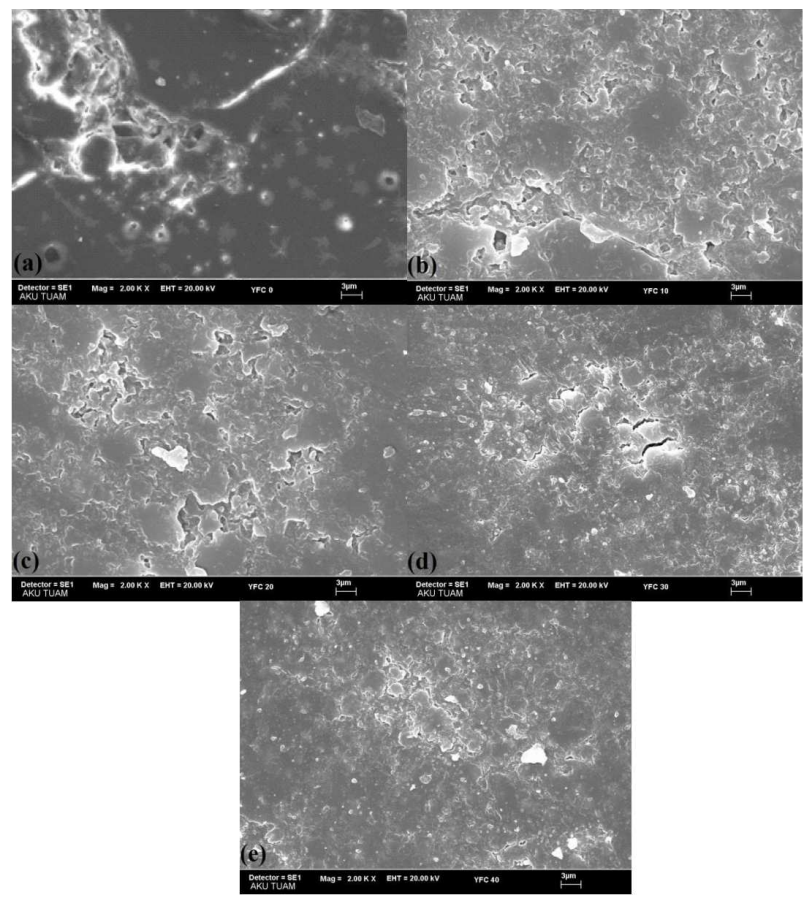

Fig. 6. The wear SEM micrographs of epoxy composites after tribometry, for various blast furnace slag concentrations: (a) pure epoxy, (b) 10\% BFS, (c) 20\% BFS, (d) $30 \%$ BFS, (e) $40 \%$ BFS.

degree of hardness values of the BFS blended polymer composites. While such deformations as tears, breaks and cracks were observed on pure epoxy samples, only one trace was observed on the BFS added samples after the wear tests.

\section{Conclusions}

The objective of this report has been to describe the wear and friction characteristics of epoxy-based polymer composites, as well as the mechanism of how the blast furnace slag can enhance the properties of polymer composites. The following conclusions can be derived from the present study:

- Using blast furnace slag containing material increases the hardness values of the samples, compared to the pure epoxy samples.

- The surface roughness values of the pure epoxy samples and samples with low content of BFS material were close to each other. The use of blast furnace slag containing material in polymer composites provides higher friction coefficient, compared to pure epoxy series. The friction coefficient of all series increased with the increase in the load.

- Wear strength was higher at high BFS ratio than at low BFS ratio due to more homogenous distribution of particles with high resistance to abrasion. The enhancement in the wear resistance of the polymer composites at $30 \mathrm{~N}$ was about 2.84 times greater with the increase in the content of BFS. 
- An increase in load has led to the emergence of the "border effect" on the surface. The border effect has led to an increase in friction coefficient at higher loading conditions.

- While such deformations as tears, breaks and cracks were observed on the pure epoxy samples, only one trace was observed on the BFS added samples after the wear tests.

- Consequently, the results indicate that the use of blast furnace slag, as an additive material in epoxy based polymer composites, has lead to a notable improvement in the wear resistance, friction coefficient and surface quality.

\section{Acknowledgments}

This research was carried out under project number 114M155 of the Scientific and Technical Research Council of Turkey (TUBITAK).

\section{References}

[1] J.W. Hamling, R.W. Kriner, Cement Concrete Aggreg. 14, 13 (1992).

[2] F.J. Hogan, J.W. Meusel, Cement Concrete Aggreg. 3, 40 (1981).

[3] C. Duos, J. Eggers, Rpt. No. FHWA/LA-99/336, Louisiana Trans. Res. Center, Baton Rouge, Louisiana, Oct. 1999, p. 45.

[4] I. Akkurt, S. Emikönel, F. Akarslan, K. Günoğlu, Ş. Kilinçarslan, I. Uncü, Acta Phys. Pol. A 128, B-53 (2015).
[5] Y. Ceylan, H. Yumurtaci Aydogmus, K. Usta, A. Usta, N. Ceylan, H. Yilmaz, Acta Phys. Pol. A 130, 167 (2016).

[6] J. Barton, A. Niemczyk, K. Czaja, Ł. Korach, B. Sachermajewska, Chemik 68, 280 (2014).

[7] S. Ekşi, K. Genel, Acta Phys. Pol. A 128, B-59 (2015).

[8] I.K. Yilmazcoban, S. Doner, Acta Phys. Pol. A 130, 342 (2016).

[9] I. Abdalrazaq, W.A. Soud, O.S. Abdullah, J. Eng. Development 17, 1813 (2013).

[10] N. Ozsoy, M. Ozsoy, A. Mimaroglu, Acta Phys. Pol. A 128, B-55 (2015).

[11] B. Suresha, B.N. Ravi Kumar, M. Venkataramareddy, T. Jayaraju, Mater. Design 31, 1993 (2010).

[12] T. Uygunoglu, I. Gunes, B. Witold, Mater. Res.Ibero-Am. J. Mater. 18, 1188 (2015).

[13] M. Uzun, K. Yildiz, Acta Phys. Pol. A 128, B-337 (2015).

[14] A. Günen, Acta Phys. Pol. A 130, 217 (2016).

[15] A.P. Harsha, Wear 271, 942 (2011).

[16] P.H. Shipway, N.K. Ngao, Wear 255, 742 (2003).

[17] J. Cayer-Barrioz, D. Mazuyer, Ph. Kapsa, A. Chateauminois, G. Robert, Polymer 45, 2729 (2004).

[18] A. Golchin, G.F. Simmons, S. Glavatskih, B. Prakash, in: 15th Nordic Symp. Tribology - NordTrib 2012, Norway 2012, p. 12

[19] W. Brostow, P. Kumar, D. Vrsaljko, J. Whitworth, J. Nanosci. Nanotechnol. 11, 3922 (2011).

[20] O. Olea-Mejla, W. Brostow, E. Buchman, J. Nanosci. Nanotechnol. 10, 8524 (2010).

[21] T. Uygunoğlu, W. Brostow, G. Ibrahim, Polimeros 25, $271(2015)$. 